\title{
A SEPARAÇÃO DE PODERES, O TRIBUNAL CONSTITUCIONAL E A "JUDICIALIZAÇÃO DA POLÍTICA"
}

\author{
THE SEPARATION OF POWERS, THE CONSTITUTIONAL COURT AND THE “JUDICIALIZATION OF
}

POLITICS"

Rubens Beçak ${ }^{*}$

\begin{abstract}
Resumo:
Tratar do Tribunal Constitucional como partícipe do processo político demanda, preliminarmente, tratar da questão do evolver da Teoria da Separação dos Poderes. Montesquieu formulou "receita de arte política", sem nunca pretender uma classificação científica das funções do Estado.

Mesmo relembrando que já fizera a previsão do veto, nem por isso perdeu este a pecha de advogar a separação exclusiva dos poderes...

Certamente, isto decorreu também da inclusão deste princípio como "fórmula constitucional" em um grande número de constituições surgidas na leva revolucionária.

Aqui cabe observação acerca da rigidez deste próprio sistema. Se num primeiro momento parece de ordem absoluta, logo se evidencia que o preceito diz respeito à atividade preferencial e primeira daquele Poder.

Isto porque logo fica claro que os poderes estatais exercem funções que, em tese, não lhes seriam atinentes. Isto só ficou mais evidente com o advento da teoria dos checks and balances.

Comentamos também alguns desenvolvimentos específicos de áreas de atuação dos Poderes por sobre os outros Poderes.

Deste verdadeiro "entre-cruzar" de funções, decorreram uma série de fenômenos, dentre os quais destacamos a "judicialização da Política" e "politização da Justiça". Focando a análise no primeiro deles, já há que se verificar se episódios como a atuação recente de nosso STF não estaria a exigir reflexão sobre um eventual deslocamento da atividade política para órgãos não escolhidos pelo critério democrático tradicional. O desequilíbrio hoje é flagrante, gerando preocupações e exigindo este repensar, o qual propomos em breve síntese.

Palavras-chave: Teoria da separação dos poderes. Não-rigidez. Atividade preferencial. Checks and balances. Atuação dos poderes sobre outros poderes. "Entre-cruzar" de funções. "Judicialização da política". Reflexões.
\end{abstract}

\begin{abstract}
:
To consider the Constitutional Court as a participant of the political process requires, first of all, the study of the separation of powers doctrine. Montesquieu developed the "recipe of the political art", without ever intending a scientific classification of the State's functions. Even with the provision of the veto, he did not lost, however, the mark of an apologist of the exclusive separation of powers. Certainly it is a consequence of the insertion of this principle as a "constitutional formula" in a
\end{abstract}

\footnotetext{
Mestre e Doutor em Direito Constitucional pela Faculdade de Direito da Universidade de São Paulo. Professor da Faculdade de Direito de Ribeirão Preto da Universidade de São Paulo. Membro efetivo do IASP - Instituto dos Advogados de São Paulo. rubens.becak@gmail.com.
} 
large amount of constitutions published in revolutionary ages. A remark about the rigidity of this system is necessary. If, in a first moment, the rigidity is an absolute character, on can easily note that this principle concerns the preferential and main activity of this power. This character is highlighted because state powers perform functions that, in principle, were not their attributions, evidenced by the checks and balances doctrine. Some specific developments in the performance of power spheres in the other performance of power spheres were made. In this real interrelation of functions, a series of facts happened, specially the judicialization of politics, and politization of justice. Focusing the analysis in the first one, a reflection whether the recent performance of the Brazilian Supreme Court require an eventual shift of political activity from organs not-elected by traditional democratic criteria. The unbalance of the powers is evident, causing concern and requiring a reflection about these facts.

Keywords: Separation of powers doctrine. Checks and balances. Performance of powers on the other powers sphere. Interrelation of functions. Judicialization of politics.

\section{Introdução}

Tratar do tema proposto, qual seja a função do Tribunal Constitucional como regulador do processo político demanda necessariamente, e em primeiro lugar, tratar da questão do evolver da Teoria da Separação dos Poderes, de seu prisma estático - pelo menos na maneira como era vista pelos seus primeiros intérpretes - para o atual, mais dinâmico.

Já tivemos a oportunidade de explorar o tema no nosso A Hipertrofia do Poder Executivo, ${ }^{1}$ onde expusemos demoradamente a evolução da idéia da identificação e separação dos poderes desde a Antigüidade até os nossos dias.

Foi inegavelmente com Montesquieu, no seu famoso Do espírito das leis, que o tema adquiriu densidade, determinante na sua divulgação e consagração como postulado democrático. No dizer de Pinto Ferreira: "Finalmente aparece o grande mestre da doutrina". ${ }^{2}$

Montesquieu formulou aquilo que Manoel Gonçalves Ferreira Filho sempre acertadamente definiu como "receita de arte política", ${ }^{3}$ realçando que o ilustre filósofo nunca pretendeu uma classificação científica das funções do Estado.

\footnotetext{
BEÇAK, Rubens. A hipertrofia do executivo brasileiro: o impacto da Constituição de 1988. Campinas: Millennium, 2008.

2 FERREIRA, Pinto. Curso de direito constitucional. 12. ed. ampl. e atual. São Paulo: Saraiva, 2002. p. 87.

3 FERREIRA FILHO, Manoel Gonçalves. A democracia no limiar do século XXI. São Paulo: Saraiva, 2001. p. 120.
} 
Aliás, não custa relembrar, temos dúvidas até se o pensador pensou algo realmente tão estático quanto alguns de seus intérpretes sugeriram. ${ }^{4}$ Basta relembrar da previsão da figura do veto, real interferência do Poder Executivo no processo legiferante.

Nem por isso perdeu o castelão de la Brède a pecha de advogar a separação exclusiva dos poderes...

Certamente, isto decorreu também da inclusão deste princípio como "fórmula constitucional" em um sem-número de constituições surgidas na leva da "era das revoluções". ${ }^{5}$ Uma simples leitura do art. 16 da famosa Declaração de $1789,{ }^{6}$ primeiro e mais representativo documento dessa época, nos mostra esta utilização.

Sendo exportada mundo afora, mormente a onda revolucionária citada, vis as constituições das ex-colônias britânicas ${ }^{7}$ e a francesa de $1791,{ }^{8}$ auferir-se-á eficácia positiva às formulações políticas do Barão. Sua consagração vem com a famosa Constituição dos EUA, de 1787.9

De qualquer forma, o fundamental na teoria montesquiana foi aliar à identificação de determinada função estatal, além do seu desempenho por um poder

4 Já dissemos: "Entretanto, ressalte-se que, apesar de sobejo, o que prevaleceu, primeiro na direta aplicação das teses de Montesquieu nas constituições liberais então elaboradas e, mais tarde, na copiosa doutrina que se formou, foi a idéia dogmática acerca da Teoria da Separação dos Poderes, algo que Montesquieu jamais pretendera". Cf. BEÇAK, Rubens. A hipertrofia do executivo brasileiro: o impacto da Constituição de 1988. Campinas: Millenium, 2008.

5 Tomamos emprestada a expressão e conceito desenvolvidos por Eric Hobsbawm, no seu "The Age of Revolution", vindo à luz em 1962.

6 “'(...)

Art. 16. Toute société dans laquelle la garantie des droits n’est pas assurée, ni la séparation des pouvoirs déterminée, n'a point de constitution. (...)."

DUVERGER, Maurice. Constitutions et documents politiques. $8^{\text {ème }}$ ed. Paris: Presses Universitaires de France, 1978. (Thémis.)., p. 10.

7 Especialmente as duas primeiras, Virgínia, em 1776, e Massachusetts, em 1780.

8 “(...)

Titre III

Des Pouvoirs Publics

ARTICLE PREMIER. La Souveraineté est une, indivisible, inaliénable et imprescriptible. Elle appartient à la Nation; aucune section du peuple, ni aucun individu, ne peut s'en attribuer l'exercice.

ART. 2. La Nation, de qui seule émanent tous les Pouvoirs, ne peut les exercer que par délégation. - La Constitution française est représentative: les représentants sont le Corps législatif et le Roi.

ART. 3. Le Pouvoir législatif est délégué à une Assemblée Nationale composée de représentants temporaires, librement élus par le peuple, pour être exercé par elle, avec la sanction du Roi, de la manière qui sera déterminée ci-après.

ART. 4. Le Gouvernement est monarchique: le Pouvoír exécutif est délégué au Roi, pour être exercé sous son autorité, par des ministres et autres agents responsables, de la manière qui sera déterminée ci-après.

ART. 5. Le Pouvoir judiciaire est délégué à des juges élus à temps par le peuple.

$(\ldots)$ ")

DUVERGER, Maurice. Constitutions et documents politiques. $8^{\text {ème }}$ ed. Paris: Presses Universitaires de France, 1978. (Thémis.). p. 13.

9 Cf. texto em DUVERGER, Maurice. Constitutions et Documents Politiques. $8^{\text {ème }}$ ed. Paris: Presses Universitaires de France, 1978. (Thémis.). p. 410. 
específico do Estado, a recomendação de que não fossem atribuídas a mais de um poder cada função e, ademais, que esses Poderes desempenhassem suas funções sem imiscuírem-se nas esferas alheias.

E aqui é importante fazer observação acerca da rigidez deste próprio sistema. Se num primeiro momento parece de ordem absoluta, i.e., cada Poder desempenha tãosó uma única função, logo se evidencia que o preceito absoluto diz respeito à atividade preferencial e primeira daquele Poder.

Sim, porque logo fica claro que os poderes estatais exercem funções que, em tese, não lhes seriam atinentes, em realidade o fazem como atribuições necessárias à realização de suas próprias tarefas. ${ }^{10}$

\footnotetext{
${ }^{10}$ Dentre as inúmeras, excelentes e conhecidas referências e exemplificações sobre o fato de o exercício de funções secundárias por um Poder não desvirtuar sua função precípua - antes, fornecer subsídios para o seu melhor desempenho -, trazemos a de SOUSA, Leomar Barros Amorim de. A produção normativa do Poder Executivo. Brasília: Brasília Jurídica, 1999. p. 37-38:
}

“(...)

Há que entender, portanto, que cada órgão, na sua respectiva área de competência, terá um espaço preferencial, prioritário ou prevalente. O órgão do Legislativo, dessa forma, estará sempre vocacionado preferencialmente para editar normas jurídicas gerais, mas sem o monopólio ou exclusividade de tal tarefa. Assim, encontrar-se-á a permissão, em várias Constituições de Estados modernos, para que o chefe do ramo executivo emita decretos gerais com força de lei. O departamento legislativo permanece como órgão ordinário de feitura das leis; mas ao Executivo dá-se-lhe uma competência legislativa extraordinária. Veja-se o caso dos decretos-leis ou das medidas provisórias que serão mais adiante estudadas. São atos legislativos com força de lei adotados pelo chefe do Executivo.

O Executivo também exerce função legislativa quando participa por meio de veto, no ciclo de formação da lei, em ordem a impedi-la de entrar no mundo jurídico; ou quando a sanciona, aprovando-a para que tenha validade; ou ainda quando inicia o processo legislativo, encaminhando projeto de lei ao Parlamento.

O Judiciário, por seu turno, algumas vezes atua com atribuições que materialmente muito se assemelham à função legislativa. A elaboração dos regimentos internos dos tribunais, autorizada no art. 96 da Constituição, 'dispondo sobre a competência e o funcionamento dos respectivos órgãos jurisdicionais e administrativos', em muito se assemelha à lei; pode afirmar-se que algumas dessas normas interna corporis, quando possuem uma certa generalidade e projetam efeitos externos, em certa medida são materialmente leis.

Não parece difícil sustentar que a Suprema Corte também exerce uma 'função legislativa' quando proclama a inconstitucionalidade de uma lei, de um decreto-lei ou medida provisória, ou de um decreto regulamentar, inclusive pelo atributo do efeito erga omnes que a decisão ostenta. Em tal situação atua o Tribunal como 'legislador' no sentido negativo, mas nem por isso deixando de inovar a ordem jurídica em caráter inaugural, embora de modo ablativo. Igual fenômeno ocorre nos países que adotam o sistema do stares decisis - ou, como se está pretendendo introduzir no Brasil, a súmula vinculante -, com validade inclusive para a Administração, ficando os tribunais e juízos inferiores obrigados a seguir o precedente.

E o Legislativo exerce função jurisdicional típica, embora fortemente plasmada pelo componente político, quando atua como Tribunal no processo de impeachment para julgamento do Presidente da República nos crimes de responsabilidade, com o objetivo de destituí-lo do cargo. Desse modo, em relação ao Presidente, entra em cena, no primeiro momento, a Câmara dos Deputados, para autorizar a instauração do processo. E, em seguida, o Senado da República, para processar e julgar o feito, sendo dirigido o 'Tribunal Político' (que atua quase sempre no sentido político-partidário, e poucas vezes, ou nenhuma, no sentido grego) pelo Presidente do Supremo Tribunal Federal. O Senado tem ainda competência constitucional para julgar os magistrados do Supremo Tribunal Federal, o Procurador-Geral da República e o Advogado-Geral da União nos crimes de responsabilidade (arts. 51, I, e 52, I e II, CF). (...)" 
Assim, os exemplos, tão citados, de o Poder Legislativo assumir funções executivas, quando realiza o seu próprio orçamento, ou assumir funções judiciais, quando, em determinadas situações, é transformado em câmara de julgamento (o impeachment), não lhe tiram o condão de ser, em tarefa primeira, o encarregado da legislação.

Também o Executivo. Ao reger a administração, por exemplo, pode perfeitamente baixar instruções (poder de legislar) ou mesmo quando, onde é possível, exercer o contencioso administrativo (julgar), tarefas estas que, mesmo realizadas na sua cepa, não lhe subtraem o legado de ser o responsável, primordialmente, pela execução.

E o Judiciário, da mesma forma. Quando vota o seu orçamento, realiza tarefa executiva. Ao sistematizar alguns procedimentos judiciais, exerce inequívoca tarefa legislativa. Entretanto, tal como os outros dois poderes, não perde a característica de ter atividade preferencial, qual seja, a de julgar.

Não cansaremos tão dileta e ilustre platéia com uma exposição que certamente é de seu conhecimento, mas vamos sim diretamente ao ponto de frisar que a idéia estanque de que os poderes desempenham funções meramente adstritas às suas denominações sofreu inegável abalo com o advento da teoria dos checks and balances ou seja, como já denominamos, ${ }^{11}$ a adaptação norte-americana da Teoria da Separação dos Poderes, de Monstesquieu, à dinâmica necessária à fundação da então novel Federação estadunidense.

Se a formulação de uma adaptação empírica ao modelo original montesquiano já demonstra desde cedo a necessidade de os poderes constituídos trabalharem em sintonia, realçando-se o caráter não absoluto da separação, observamos ainda, ao longo da História alguns desenvolvimentos específicos de áreas de atuação dos Poderes por sobre os outros Poderes.

Estes passam a assumir tarefas que, num primeiro recorte não lhes tinham sido destinadas, produzindo uma série de estudos mais ou menos abrangentes, às vezes mais focados até mesmo na Ciência Política do que no Direito.

\section{Desenvolvimentos posteriores à formulação dos checks and balances}

Assim, observamos, objeto de nosso próprio estudo, já referido, um avançar do Poder Executivo na questão da legiferação, assumindo no início, uma posição tímida e, depois, com o passar do tempo, ganhando a linha de frente do processo.

Como já dissemos:

\footnotetext{
11 "É esta "revisão" do modelo preexistente que passou a ser conhecida como teoria dos checks and balances". Cf. BEÇAK, Rubens. A hipertrofia do executivo brasileiro: o impacto da Constituição de 1988. Campinas: Millennium, 2008. p. 31-32.
} 
$\mathrm{O}$ século $\mathrm{XX}$ demonstrou que em todos os Estados do mundo, qualquer que seja o regime, o Executivo "furtou" do Legislativo sua tarefa institucional de origem, qual seja o legislar. ${ }^{12}$

Veja-se, no Brasil, a questão da legiferação pelo Executivo, notadamente a utilização da medida provisória. ${ }^{13}$

Nos aventuramos a dizer que dificilmente consideramos a possibilidade de reversão deste quadro...

Com relação ao Poder Legislativo, igualmente. De uma posição de ente detentor (praticamente monopolista) da atividade legislativa, desenho que the foi destinado na Teoria da Separação dos Poderes, vai evolver para galgar as raias de verdadeiro poder primus inter pares, notadamente com o predomínio da idéia de que seria o poder mais próximo da vontade geral, por ser aquele que é composto por representantes do povo.

Se tal predomínio era sintomático, especialmente por volta do final do século XIX, subseqüentemente, é corrente discorrer, passou por imensa perda de poder político, vindo a ser esvaziado de um real peso na atividade legiferante, mormente em decorrência do processo hipertrófico por que passou o Poder Executivo. ${ }^{14}$

Mas é sabido também que o Poder Legislativo vai compensar esta perda de peso na legiferação, com um aumento significativo de seu poder fiscalizatório.

Do resgate do impeachment, até a alguns anos visto como mera figura de realce histórico (vide casos nos anos 90 do Brasil, Venezuela, EUA, Peru, Equador etc.) até a assunção de um papel fiscalizatório político totalmente novo, como a fiscalização do processo político, não-só pela utilização de mecanismos investigatórios (no Brasil, as famosas CPIs), como pelo próprio debate acerca de políticas públicas etc.

Manoel Gonçalves Ferreira Filho já mostrava no seu Do processo legislativo ${ }^{15}$ que o Poder Legislativo assumiu muito mais o papel passivo, frente à iniciativa cada vez mais dinâmica do Poder Executivo, como também, e aqui o mestre lembra Jean de

${ }_{12}$ Cf. BEÇAK, Rubens. A hipertrofia do executivo brasileiro: o impacto da Constituição de 1988. Campinas: Millennium, 2008. p. 43.

${ }_{13}^{13}$ Cf. levantamento de autores brasileiros que trabalham o tema em Id. Ibid., p. 14.

${ }^{14}$ Mas não se esqueça, ainda, da grande perda de prestígio que este Poder passou, notadamente nas primeiras décadas do século passado, aliás, também uma das causas da hipertrofia executiva.

${ }^{15}$ FERREIRA FILHO, Manoel Gonçalves. Do processo legislativo. 5. ed. rev. ampl. e atual. São Paulo: Saraiva, 2002. p. 131-132. 
Soto “(...) o de refletir sobre a política governamental à luz dos contactos com a opinião pública. (...)". ${ }^{16 / 17}$

E continua: "Essa tendência, curiosamente, recoloca os Parlamentos em posição semelhante à que ocupavam ao surgirem, na Idade Média (...)”. ${ }^{18}$

Em estudo acerca do papel do Poder Legislativo no século XXI, Caggiano ${ }^{19}$ tece considerações na mesma linha, mostrando a apatia dos legislativos no século XX, exatamente por terem perdido a capacidade de produção legislativa. A Autora diz claramente:

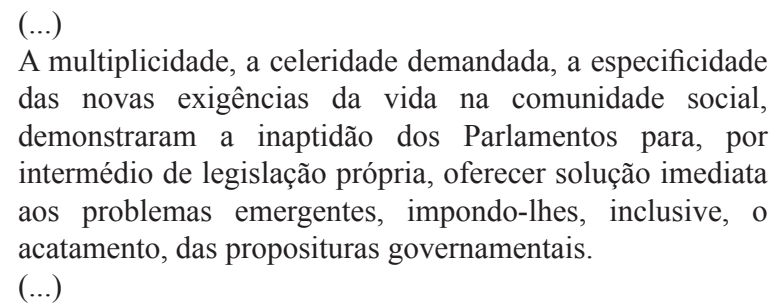

Isto, é bem verdade, realça o novo caráter de prestígio do Legislativo, com as tarefas de controle político, notadamente após a década de $90 .{ }^{20 / 21}$

É claro que os Legislativos, no geral, continuam a desempenhar importante papel legiferante, entretanto se nota que se acentuou o seu papel de agentes fiscalizadores e controladores.

Esta verdadeira "usurpação" de funções originais de um Poder por outro Poder político, desfazendo aquela aparência de estaticidade que já citamos, também não passou incólume pelo Poder Judiciário.

Com o desenvolvimento do controle de constitucionalidade, já no início do século XIX, com o famoso caso Marbury vs. Madison, vai o Poder Judiciário, no

\footnotetext{
${ }^{16}$ Jean de Soto apud FERREIRA FILHO, Manoel Gonçalves. op. cit., p. 131: La Loi et le règlement dans la Constitution du 4 octobre 1958, Revue du Droit et de la Science Politique, Paris, v. 75, n. 2, p. 271, mar./abr. 1959.

${ }^{17}$ A respeito da tendência crescente do Legislativo no papel fiscalizador, cf., também, CARRION, Eduardo K. M. Sistemas de governo e controle do poder. Revista de Informação Legislativa, Brasília, n. 113, p. 5-14, jan./ mar. 1992. Também SOARES, Rosinethe Monteiro. Fiscalização e controle do Executivo pelo Legislativo. Revista de Informação Legislativa, Brasília, n. 101, p. 147-160, jan./mar. 1989.

${ }^{18}$ FERREIRA FILHO, Manoel Gonçalves. Do processo legislativo. 5. ed. rev. ampl. e atual. São Paulo: Saraiva, 2002. p. 131.

${ }^{19}$ CAGgianO, Monica Herman Salem. O Parlamento no cenário político do século XXI. Revista do Advogado, São Paulo, n. 73, p. 146-166, nov. 2003. (Estudo de Direito Constitucional em homenagem a Celso Ribeiro Bastos). p. 153-154. (A citação trazida encontra-se na p. 153).

${ }^{20}$ CAGGiANO, Monica Herman Salem. op. cit., p. 154.

${ }^{21}$ A autora retoma o tema em Direito parlamentar e direito eleitoral. Apresentação de Cláudio Lembo. Barueri: Manole, 2004. p. 30 e ss.
} 
caso representado pela Suprema Corte americana, assumir papel de fiel da balança dos poderes.

Realmente. Com o desenvolvimento do controle de constitucionalidade, o Poder Judiciário vai imbuir-se do papel - mesmo que potencial - de convalidador (ou não) da vontade geral expressa na lei. ${ }^{22}$

Este papel resta muito claramente demonstrado nos EUA entre as últimas décadas do século XIX e os anos 30, quando, com a necessidade de aprovação do New Deal de Franklin Delano Roosevelt, a eficaz pressão política feita pelo popular presidente, faz, senão reverter, ao menos minudar esta realidade.

O quadro, além mares, é igualmente sintomático das novas funções assumidas pelo Poder Judiciário. Na medida em que, com a criação do controle de constitucionalidade de matriz abstrata, por Kelsen em 1920, a idéia de um Tribunal Constitucional como regulador da constitucionalidade ficou muito mais evidenciada do que no modelo americano.

$\mathrm{Na}$ idéia kelseniana, o Tribunal Constitucional já vem desenhado objetivamente como o garante da Constituição, o que, pensamos, só fez gizar este papel.

Adroaldo Leão assevera:

(...)

Destoando do modelo americano, propõe Hans Kelsen, novo modelo, a cargo de um tribunal político denominado de Constitucional, a ser integrado por membros recrutados entre os três Poderes: espécie de poder moderador desvinculado do Poder Judiciário e do seu tecnicismo jurídico.

Aquele consagrado pensador, na Áustria, elaborou um projeto de Constituição por solicitação do Chanceler Renner, no qual criou o referido Tribunal, em 1920, tendo sido o seu primeiro Presidente.

$(\ldots)^{23}$

Deste verdadeiro "entre-cruzar" de funções - pelo menos do ponto de vista do recorte original da Teoria da Separação dos Poderes - processo o qual procuramos, em brevíssima exposição, apontar, decorreram uma série de fenômenos, dentre os quais destacamos os (relativamente) recentes "judicialização da Política" e "politização da Justiça".

\footnotetext{
${ }^{22}$ Sobre o processo, detalhando a criação, evolução e alcance do controle de constitucionalidade, cf. ACOSTA SÁNCHEZ, José. Formación de la Constitución y Jurisdicción Constitucional. Madrid: Tecnos, 1998. cap. IV, especialmente p. 123-126.

${ }^{23}$ Cf. LEÃO, Adroaldo. Direito à Jurisdição Constitucional Democrática. Disponível em: <http://www.unifacs. br/revistajuridica/edicao_abril2004/docente/doc03.doc>. Acesso em: 14 jan. 2008. p. 5.
} 


\section{A judicialização da política}

Estes processos têm recebido cada vez mais atenção da doutrina, cabendonos uma breve consideração a respeito do primeiro deles

Já em pioneiro estudo, Klaus Schaich, em 1982, ${ }^{24}$ mostrava que um Tribunal Constitucional encarregado permanentemente do controle legislativo, acabará tendendo a utilizar no seu exame não-só o resultado da lei, mas também o exame do processo pelo qual ela exsurge.

O autor citado tece considerações oportunas e cautelosas sobre o tema, preocupando-se, sobretudo, com o processo legislativo, advertindo, afinal, que a constância da apropriação pelo Tribunal de processo que não lhe caberia na origem, poderia, paradoxalmente, conduzir à agudização da eventual falta de responsabilidade do legislador.

Entendemos e partilhamos da angústia do Autor, especialmente se considerarmos que o processo de deslocamento da atividade legislativa para os Tribunais parece vir se acelerando e, sobretudo, configurando processo de latitude mundial, de certa forma inexorável.

Aqui queremos lembrar o magistério de John Ferejohn, ${ }^{25}$ o qual, estudando o fenômeno observa:

\section{(...)}

Em contrapartida, a aplicação da lei deveria ocorrer nos tribunais. A aplicação da lei pode ser controversa, mas espera-se que seja tratada primordialmente como um assunto técnico em que o que importa é escolher o princípio adequado à resolução do contencioso. $\mathrm{O}$ dever dos juízes e dos funcionários do Judiciário é fornecer tribunas eqüitativas e imparciais para que as partes em disputa possam resolver seus conflitos de acordo com as normas legais pré-existentes e válidas. Os tribunais não são lugares onde se formulam normas genéricas e prospectivas, tampouco são lugar para a atividade política de facções. As duas atividades - a legislativa e a judiciária - devem ser conduzidas separadamente, de acordo com princípios distintos.

(...)

\footnotetext{
24 Cf. In: FAVOREAU, Louis et al. Informe general introductorio. Tribunales constitucionales europeos y derechos fundamentales. Madrid: Centro de Estudos Constitucionales, 1984.

25 FEREJOHN, John. Judicializing Politics, Politicizing Law. Disponível em: <http://www.law.duke/journals/ 65L.CPFerejohn>. Acesso em: 17 jan. 2008.
} 
As preocupações do Autor são aqui partilhadas, na medida em que observase, e o nosso foco é o Brasil, um acirramento do fenômeno, com possíveis conseqüências a provocar cautela.

Episódios como as relativamente recentes decisões de nosso STF, no sentido da interpretação da denominada "cláusula de barreira" ou mesmo da fidelidade partidária, exigem reflexão se não estaríamos às portas de um deslocar da atividade política para órgãos não escolhidos pelo critério democrático tradicional.

Não estamos a dizer, por claro, que falte legitimidade a nosso Judiciário. ${ }^{26}$ É meramente um refletir sobre o real valor da democracia, enquanto fator necessário ao desenvolvimento da atividade política.

Entendemos que o papel do Judiciário deve ser sim o de colmatar os espaços deixados omissos pelo legislador - por uma série de fatores, é bem verdade - mas talvez, como, aliás, é a reflexão já citada de Klaus Schlaich, seja o caso de o Judiciário, mais especificamente o Tribunal Constitucional, remanescer apenas como mediador, diríamos regulador do processo.

Tal proceder asseguraria que o processo político como um todo permanecesse adstrito aos Poderes democraticamente incumbidos, sem os riscos evidentes de a vontade geral vir a ser exercida de outra forma.

Não se deve deixar de mencionar que os próprios Poderes incumbidos do processo político têm contribuído para esta situação, na medida em que se observa que muitas vezes são estes próprios Poderes, notadamente o Legislativo, que recorrem ao STF, buscando respostas políticas deste órgão, em esgotar suas tradicionais formas de resolução. ${ }^{27}$

Este é um dos motivos porque vem se avolumando a discussão sobre a necessidade de transformação (entendemos, mais do que oportuna) do STF em Tribunal Constitucional exclusivo.

\footnotetext{
${ }^{26}$ Aliás, muito ao contrário. Lembremos, por oportuno as palavras de Jorge Miranda: “(...) Em estritos termos jurídicos, a legitimidade do Tribunal Constitucional não é maior, nem menor do que a dos órgãos políticos: advém da Constituição. E, se esta Constituição deriva de um poder constituinte democrático, então ela há-de ser, natural e forçosamente, uma legitimidade democrática.” E prossegue, mais adiante: “(...) É, justamente, por os juízes constitucionais serem escolhidos por órgãos democraticamente legitimados - em coerência, por todos quantos a Constituição preveja, correspondentes ao sistema de Governo consagrado - que eles podem invalidar actos com a força de lei. É por eles, embora por via indirecta, provirem da mesma origem dos titutares de órgãos políticos que por etes conseguem fazer-se acatar. (...)". Cf. MIRANDA, Jorge. Manual de direito constitucional. Coimbra: Coimbra Editora, 2001, t. 6, p. 117 e 121.

${ }^{27}$ Episódio sintomático é a interposição do Mandado de Segurança 27097 contra ato do Executivo que supostamente não teria observado a Resolução do Senado n. 34/07 que "teria autorizado modificações no Contrato de Confissão, Assunção, Consolidação e Refinanciamento de Dívidas, celebrado entre a União e o estado de Rondônia".
} 
O desequilíbrio hoje é flagrante, gerando preocupações e exigindo um repensar, reflexão que propomos em breve síntese.

\section{Considerações finais}

Neste artigo, procuramos apontar como desde o início que a Teoria da Separação dos Poderes de Montesquieu teve uma rigidez na fixação das atribuições cabentes a cada Poder muito mais fixada pelos comentadores das idéias do Pensador, do que de sua própria construção.

Independentemente desta ponderação inicial, percebemos também como a construção do sistema de checks and balances consolidou o entendimento da especialização dos poderes em determinadas tarefas, substituindo o entendimento da separação.

Na seqüência, a própria evolução do Estado vai provocar o surgimento de alguns fenômenos históricos, o do primado do Legislativo, na esteira do entendimento de que seria o Poder que exprime por excelência a vontade geral, a hipertrofia do Executivo, na evolução do conceito de Poder de Polícia, e finalmente, a preponderância do Judiciário, no chamado "governo dos juízes" nos EUA.

Se estes fenômenos foram examinados rapidamente, concentramo-nos depois no último deles, mais especificamente na sua aparição recente, enquanto "judicialização da política". Aí, a nossa análise e conclusão foram no sentido da necessidade de uma reflexão, mormente o fato de que poderíamos estar presenciando verdadeira "acomodação" dos órgãos de representação à situação.

São Paulo, maio de 2008.

Referências

ACOSTA SÁNCHEZ, José. Formación de la Constitución y Jurisdicción Constitucional. Madrid: Tecnos, 1998.

BEÇAK, Rubens. A hipertrofia do executivo brasileiro: o impacto da Constituição de 1988. Campinas: Millennium, 2008.

CAGGiANO, Monica Herman Salem. Direito parlamentar e direito eleitoral. Apresentação de Cláudio Lembo. Barueri: Manole, 2004.

. O Parlamento no cenário político do século XXI. Revista do Advogado, São Paulo, n. 73, p. 146-166, nov. 2003. (Estudo de Direito Constitucional em homenagem a Celso Ribeiro Bastos).

CANOTILHO, J. J. Gomes. Direito constitucional e teoria da constituição. 5. ed. Coimbra: Almedina, [2002?]. 
CARRION, Eduardo K. M. Sistemas de governo e controle do poder. Revista de Informação Legislativa, Brasília, n. 113, p. 5-14, jan./mar. 1992.

DUVERGER, Maurice. Constitutions et documents politiques. $8^{\text {ème }}$ ed. Paris: Presses Universitaires de France, 1978. (Thémis).

FAVOREAU, Louis et al. Informe general introductorio. Tribunales constitucionales europeos y derechos fundamentales. Madrid: Centro de Estudos Constitucionales, 1984.

FEREJOHN, John. Judicializing Politics, Politicizing Law. Disponível em: <http://www.law.duke. edu/jornals/65L.CPFerejohn>. Acesso em: 17 jan. 2008.

FERREIRA, Pinto. Curso de direito constitucional. 12. ed. ampl. e atual. São Paulo: Saraiva, 2002. . Princípios gerais do direito constitucional moderno. 5. ed. ampl. e atual. São Paulo: Revista dos Tribunais, 1971. 2 t.

FERREIRA FILHO, Manoel Gonçalves. A democracia no limiar do século XXI. São Paulo: Saraiva, 2001 .

. Do processo legislativo. 5. ed. rev. ampl. e atual. São Paulo: Saraiva, 2002.

LEÃO, Adroaldo. Direito à Jurisdição Constitucional Democrática. Disponível em: <http://www.unifacs. br/revistajuridica/edicao_abril2004/docente/doc03.doc>. Acesso em: 14 jan. 2008.

MIRANDA, Jorge. Manual de direito constitucional. 4. ed. rev. e atual. Coimbra: Coimbra Editora, 1990. t. 1.

. Manual de direito constitucional. Coimbra: Coimbra Editora, 2001. t. 6.

MONTESQUIEU, Charles-Louis de Secondat, Barão de la Brède e de. Do espirito das leis. Tradução de Fernando Henrique Cardoso e Leôncio Martins Rodrigues. São Paulo: Abril Cultural, 1979. (Os Pensadores.)

PIÇARRA, Nuno. A separação dos poderes como doutrina e princípio constitucional: um contributo para o estudo das suas origens e evolução. Coimbra: Coimbra Editora, 1989.

SOARES, Rosinethe Monteiro. Fiscalização e controle do Executivo pelo Legislativo. Revista de Informação Legislativa, Brasília, n. 101, p. 147-160, jan./mar. 1989.

SOUSA, Leomar Barros Amorim de. A produção normativa do Poder Executivo. Brasília: Brasília Jurídica, 1999.

SOUZA JUNIOR, Cezar Saldanha. O tribunal constitucional como poder: uma nova teoria da divisão dos poderes. São Paulo: Memória Jurídica, 2002. 